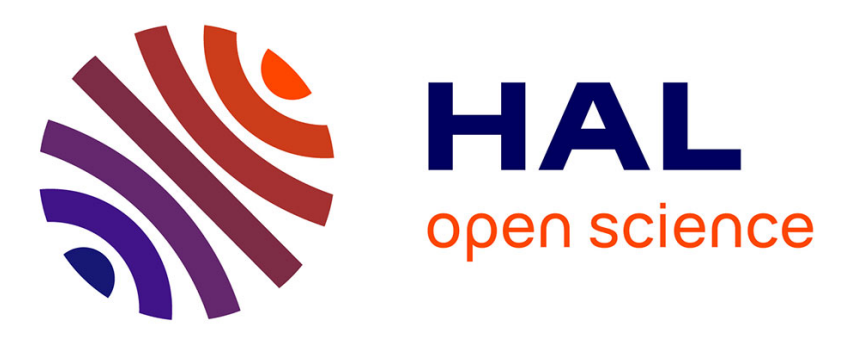

\title{
Influence irradiation by high energy heavy ions on piezoelectric, elastic and dielectric properties of $\mathrm{ZnO}$ single crystals
}

\author{
I. Silvestrova, Yu. Pisarevsky, V. Skuratov, A. Didyk, I. Kuzmina
}

\section{To cite this version:}

I. Silvestrova, Yu. Pisarevsky, V. Skuratov, A. Didyk, I. Kuzmina. Influence irradiation by high energy heavy ions on piezoelectric, elastic and dielectric properties of $\mathrm{ZnO}$ single crystals. Journal de Physique IV Proceedings, 1994, 04 (C2), pp.C2-211-C2-214. 10.1051/jp4:1994227 • jpa-00252495

\section{HAL Id: jpa-00252495 https://hal.science/jpa-00252495}

Submitted on 1 Jan 1994

HAL is a multi-disciplinary open access archive for the deposit and dissemination of scientific research documents, whether they are published or not. The documents may come from teaching and research institutions in France or abroad, or from public or private research centers.
L'archive ouverte pluridisciplinaire HAL, est destinée au dépôt et à la diffusion de documents scientifiques de niveau recherche, publiés ou non, émanant des établissements d'enseignement et de recherche français ou étrangers, des laboratoires publics ou privés. 


\title{
Influence irradiation by high energy heavy ions on piezoelectric, elastic and dielectric properties of $\mathrm{ZnO}$ single crystals
}

\author{
I.M. SILVESTROVA, Yu.V. PISAREVSKY, V.A. SKURATOV*, A.Yu. DIDYK* and \\ I.P. KUZMINA
}

Institute of Crystallography, Russian Academy of Sciences, Moscow, Russia

* Joint Institute for Nuclear Research, Dubna 141980, Russia

\begin{abstract}
C}^{12}(90 \mathrm{MeV})$ and $\mathrm{Ne}^{22}(160 \mathrm{MeV})$ ion irradiation effects on dielectric, piezoelectric and electromechanical properties of $\mathrm{ZnO}$ single crystals have been studied. It was hown that high energy heavy ion irradiation leads to significant changes in electromechanical properties of piezoelectric materials.
\end{abstract}

\section{1 - INTRODUCTION}

The last few years, high energy ion accelerators became available for solid state study and now high energy ion implantation is one of the most perspective methods of structural modification of different solids. At variance from low energy ion irradiation, the dominating electron stopping mechanisms of the energetic ions is the physical basis of the high energy ion implantation effects the most important of which seem to be selfannealing of the radiation damage, the increase of the defect thermal stability, the impurity migration along the ion tracks and the formation of high pressure local regions $[1,2]$. For energy more than $1 \mathrm{MeV} / \mathrm{a} . \mathrm{m}$.u. ion ranges can exceed dozens and hundreds of micrometers which permit to change the properties of bulk irradiated materials. In ref. [3], the nature of radiation damages in $\mathrm{ZnO}$ single crystals after $90 \mathrm{MeV}$ carbon and $110 \mathrm{MeV}$ oxygen ions bombardment was investigated by using optical spectroscopy. The present report deals with the first results of experimental investigations of electromechanical properties of $\mathrm{ZnO}$ irradiated with $90 \mathrm{MeV} \mathrm{C}^{12}$ and $160 \mathrm{MeV} \mathrm{Ne}^{22}$ ions.

\section{2 - EXPERIMENTAL AND RESULTS}

Crystals were grown by hydrothermal method in alkaline media containing LiOH [4]. The samples were prepared as X-cut $(0010)$ and Z-cut $(0001)$ plates $\left(5 \times 6 \times .0 .6 \mathrm{~mm}^{3}\right)$ and Z-cut bars $\left(9 \times 2 \times 1 \mathrm{~mm}^{3}\right)$. In order to increase the electrical resistivity, all samples were annealed in lithium carbonate melting [4].

The irradiation was performed with extracted on air carbon and neon ion beams on U-200 and U400 accelerators of cyclotron complex of Flerov Laboratory of Nuclear Reactions, Joint Institute for Nuclear Research, Dubna. The first series of samples was irradiated with carbon ions and after measurements was additionally irradiated with neon ions. The temperature of crystals during irradiation never exceeded $100^{\circ} \mathrm{C}$.

In order to identify the resonances giving either thickness longitudinal vibrations of Z-cut plates, or thickness shear vibrations of X-cut plates or XZOl bar vibrations, spectra of elastic vibrations were measured before and after every stage of the ion irradiation.

Elastic moluli $\mathrm{CD}_{33}, \mathrm{CD}_{44}$ and elastic constants $\mathrm{S}^{\mathrm{E}_{11}}$ were calculated from expressions :

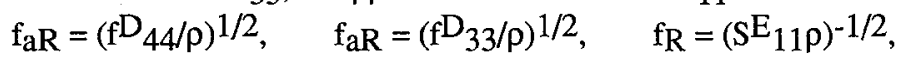

where $f_{R}$ and $f_{a R}$ - resonance and antiresonance frequencies, t-plates thickness, $\rho$-density. Dielectric constants at invariable mechanical stress and invariable deformation $\varepsilon^{\mathrm{T}_{11}}, \varepsilon \mathrm{T}_{33,} \varepsilon \mathrm{S}_{11}$ and $\varepsilon \mathrm{S}_{33}$ were measured for frequencies $1 \mathrm{KHz}$ and $10 \mathrm{MHz}$. The knowledge of resonance and antiresonance frequencies allows to determine electromechanical coupling factors of the investigated vibrations and, further, from 
these factors, elastic modula, dielectric constants are used to obtain piezoelectrical constants e33, e 15 and piezoelectrical modulus $\mathrm{d} 31$ by using expressions :

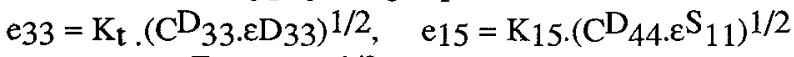

$$
\begin{aligned}
& \mathrm{d}_{31}=\mathrm{K}_{31} \cdot\left(\mathrm{S}^{\mathrm{E}} 11 \cdot \varepsilon^{\mathrm{T}} \mathrm{T}_{11}\right)^{1 / 2}
\end{aligned}
$$

Table 1 : The bulk resistance $\rho(\Omega . c m)$, dielectrical constants $\varepsilon T_{11}, \varepsilon S_{11}, \varepsilon T_{33}, \varepsilon S_{33}$, resonance frequencies $\mathrm{fR}(\mathrm{KHz})$ and $\mathrm{Q}$-factors of $\mathrm{ZnO}$ crystals before and after ion irradiation. The relative accuracy of frequency measurements- .0010 .

\begin{tabular}{|c|c|c|c|c|}
\hline Parameter & $\begin{array}{l}\text { Before } \\
\text { irrad. }\end{array}$ & $\begin{array}{l}\mathrm{C}^{12} \text { ion } \\
\text { irrad. }\end{array}$ & $\begin{array}{c}\mathrm{C}^{12} \text { and } \mathrm{Ne}^{22} \\
\text { ion irrad. }\end{array}$ & $\begin{array}{c}\text { Lit. data } \\
{[5,6]}\end{array}$ \\
\hline$\rho_{1}$ & $3.79 .10^{10}$ & $0.54 .10^{10}$ & $1.4 .10^{11}$ & \\
\hline$\rho_{2}$ & $(1.9-18.1) \cdot 10^{11}$ & $(9.0-0.57) \cdot 10^{10}$ & $(10-6) \cdot 10^{11}$ & \\
\hline$\varepsilon \mathrm{T}_{11 / \varepsilon_{0}}$ & 9.13 & 9.3 & 8.48 & $9.26 \quad 8.67$ \\
\hline$\varepsilon S_{11 / \varepsilon 0}$ & 8.68 & 8.83 & 8.1 & $8.33 \quad 8.33$ \\
\hline$\varepsilon T_{33} / \varepsilon_{0}$ & 11.26 & 11.28 & 10.66 & $11 \quad 11.26$ \\
\hline$\varepsilon_{33 / S_{0}}$ & 9.26 & 10.7 & $9.97-9.26$ & $8.84 \quad 8.81$ \\
\hline fR sl. $\mathrm{Z}$ cut & 3578.002 & 3522.001 & 3618.972 & \\
\hline fR sl. X cut & 1735.889 & 1723.502 & 1742.355 & \\
\hline$f_{R}$ & 260.885 & 260.765 & 262.033 & \\
\hline$Q$ & 2358 & 4575 & 8188 & \\
\hline
\end{tabular}

Furthermore, an analyze of elastic vibration spectra permits also to estimate or to measure by usual methods the Q-factor of corresponding resonators. Besides mentioned above parameters, the electroconductivity of samples was also measured. It should be noted that measurements were done at conditions when all samples were isolated from light at least twenty-four hours.

Experimental data are given in tables 1,2 and consist for comparison the litterature data about unirradiated crystals were obtained by hydrothermal method $[5,6]$.

Table 2 : Elastic modula $\mathrm{C}_{33}, \mathrm{CD}_{55}\left(\mathrm{~N} \cdot \mathrm{m}^{-2}\right)$, elastic compliancies $\mathrm{S}_{11}\left(\mathrm{~m}^{2} \cdot \mathrm{N}^{-1}\right.$, piezoelectric modulus d31 (CGSE), piezoelectric constants e 33 and $e_{15}$, electromechanical coupling factors $K_{\mathfrak{t}}, \mathrm{K}_{15}$, $\mathrm{K}_{31}$ before and after irradiation.

\begin{tabular}{|c|c|c|c|c|}
\hline Parameter & $\begin{array}{l}\text { Before } \\
\text { irrad. }\end{array}$ & $\begin{array}{c}\mathrm{C}^{12} \text { ion } \\
\text { irrad. }\end{array}$ & $\begin{array}{c}\mathrm{C}^{12} \text { and } \mathrm{Ne}^{22} \\
\text { ion irrad. }\end{array}$ & $\begin{array}{c}\text { Lit. data } \\
{[5,6]}\end{array}$ \\
\hline $\mathrm{CD}_{33}$ & $23.79 .10^{10}$ & $23.11 .10^{10}$ & $23.34 .10^{10}$ & $21.50 .10^{10} 22.10 .10^{10}$ \\
\hline $\mathrm{C}^{\mathrm{D}_{55}}$ & $4.74 .10^{10}$ & $4.66 .10^{10}$ & $4.77 .10^{10}$ & $4.72 .10^{10} \quad 4.48 .10^{10}$ \\
\hline$S^{E_{11}}$ & $78.89 .10^{-13}$ & $78.96 .10^{-13}$ & $78.28 .10^{-13}$ & $79.10 .10^{-13}$ \\
\hline $\mathrm{d} 31$ & $15.57 .10^{-8}$ & $15.47 .10^{-8}$ & $15.43 .10^{-14}$ & $15.43 .10^{-8} \quad 15.36 .10^{-8}$ \\
\hline e33 & $33.6 .10^{4}$ & $28.0 .10^{4}$ & $34.00 .10^{4}$ & $34.20 .10^{4} \quad 28.8 .10^{4}$ \\
\hline$e_{15}$ & $12.97 .10^{4}$ & $12.85 .10^{4}$ & $11.67 .10^{4}$ & $17.7 .10^{4} \quad 11.1 .10^{4}$ \\
\hline$K_{t}$ & $25.37 .10^{-2}$ & $19.44 .10^{-2}$ & $25.34 .10^{-2}$ & $28.2 .10^{-2} \quad 22.9 .10^{-2}$ \\
\hline $\mathrm{K}_{15}$ & $22.68 .10^{-2}$ & $22.45 .10^{-2}$ & $21.04 .10^{-2}$ & $31.5 .10^{-2} \quad 19.9 .10^{-2}$ \\
\hline K31 & $18.46 .10^{-2}$ & $18.33 .10^{-2}$ & $18.36 .10^{-2}$ & $18.9 \cdot 10^{-2} \quad 18 \cdot 10 \cdot 10^{-2}$ \\
\hline
\end{tabular}




\section{3 - DISCUSSION}

3.1 - Dielectric properties - As seen from table 1, dielectric constants of $\mathrm{ZnO}$ irradiated by $\mathrm{C}^{12}$ have been increased (the most essential variation is for $\varepsilon S_{33}$, measured at frequency $10 \mathrm{MHz}$ ). The next irradiation by $\mathrm{Ne}^{22}$ ions has led to the decrease of dielectric constants, which is manifested at low frequencies $(1 \mathrm{KHz})$ much stronger and quite weakly changed at the $10 \mathrm{MHz}$ for the value $\varepsilon_{33}$.

The bulk resistance of crystals irradiated by $\mathrm{C}^{12}$ ions in both directions (along 6 axis and perpendicular to it) decreases ( $\rho_{1}$ and $\rho_{2}$ ), but it is practically restored by a second irradiation by $\mathrm{Ne}^{22}$ ions.

3.2 - Elastic properties - Resonance frequencies are substantially influenced by the irradiation (they decrease at irradiation by $\mathrm{C}^{12}$ ions and increase above original ones by a second $\mathrm{Ne}^{22}$ ions irradiation). If we assume the density of $\mathrm{ZnO}$ to be constant, then such essential variations can be only due to the decrease of crystal stiffness after carbon irradiation and increase of stiffness after neon irradiation. Similar result has been obtained for quartz irradiation by neutrons (increasing of resonance frequency of the AT Z-cut resonators. So, at dose of $1.210^{18}$ neutron. $\mathrm{cm}^{-2}$ the relative increase of the resonator frequency was .10 [7]. In our case, for $\mathrm{ZnO}$ bar, one has detected the decrease of frequency to .0460 at the first irradiation and the increase of frequency to .4380 by second irradiation.

Data of $f_{R}=$ variation are given in table 3 .

Table 3 : Resonance frequencies of $\mathrm{ZnO}$ irradiated with high energy heavy ions and $\mathrm{SiO}_{2}$ after neutron irradiation [7].

\begin{tabular}{|l|c|c|ll|}
\hline \multicolumn{1}{|c|}{ Crystal } & Orientation & Type of irradiation & \multicolumn{2}{|c|}{ Frequency change } \\
\hline $\mathrm{SiO}_{2}$ & At-cut & neutron $1.2 .10^{18} \mathrm{~cm}^{-2}$ & increase & 0.10 \\
$\mathrm{ZnO}$ & bar & ions $\mathrm{C}^{12}$ & decrease & 0.0460 \\
& $\mathrm{X}$-cut & ions $\mathrm{C}^{12}$ & decrease & 0.7130 \\
& $\mathrm{Z}$-cut & ions $\mathrm{C}^{12}$ & decrease & 1.560 \\
& bar & ions $\mathrm{C}^{12}+\mathrm{Ne}^{22}$ & increase & 0.4380 \\
& $\mathrm{X}$-cut & ions $\mathrm{C}^{12}+\mathrm{Ne}^{22}$ & increase & 0.370 \\
& Z-cut & ions $\mathrm{C}^{12}+\mathrm{Ne}^{22}$ & increase & 1.140 \\
\hline
\end{tabular}

3.3 - Q-factor - Q-factor is the measurement of the internal friction as the rest channels of the elastic energy loosing prior and after irradiation have not been changed. In fig. 2 you can see a part of amplitude frequency characteristics of the element performing longitudinal vibration near the main resonance. This indicates the manner in which the resonance frequency decreased after carbon ion irradiation, but the Qfactor increased. After irradiation by neon ions the resonance frequency essentially increased and the $Q$ factor increased more significantly (see table 1).

3.4 - Factor of electromechanical coupling - Factor $K_{t}$ responsible for excitation of thickness longitudinal vibrations of $Z$-cut plates essentially decreases after irradiation by $C^{12}$ ions. The rest factors vary but slightly. After the second irradiation $K_{t}$ is restored and approaches its original value (Table 2 ).

3.5 - Piezoelectric moduli and constants - Piezoelectric modulus d 31 is practically not changed, but piezoelectric constant $\mathrm{e}_{15}$ decreases both at $\mathrm{C}^{12}$ ion irradiation and next irradiation by $\mathrm{Ne}^{22}$ ions. At the same time, piezoelectric constant 33 more significantly decreases at irradiation by $\mathrm{C}^{12}$ ions and is restored to its original value after irradiation by $\mathrm{Ne}^{22}$ ions. From the data obtained, one can conclude that variation of electromechanical coupling factors is mainly determined by variation of piezoelectric constants rather than by dielectric constants and elastic moduli. One should note, that crystals used in our work display their properties : values of piezoelectric constants and electromechanical coupling factors are intermediate between those of crystals described in the works [5, 6]. It seems that indicated differencies are due to different impurity contamination. 
To summarize, the data given in tables 1-3 and their next discussion show that irradiation of $\mathrm{ZnO}$ by $\mathrm{C}^{12}$ ions leads to the increase of quality of resonators independently on irradiation by neon ions. A high electrical resistivity and piezoproperties are kept constant and quality of resonators making longitudinal vibrations along $\mathrm{X}$ essentially increase when excited electrical field is applied along $\mathrm{Z}$. However, in the last case the spectrum of elastic vibrations is complicated due to additional resonances, but on the basis of the data obtained, one cannot connect it to the total increase of the quality.

Probably, radiation effects observed in $\mathrm{ZnO}$ crystals are associated with structural modifications that take place at irradiation and also with the processes of redistribution of impurities. A possible process of redistribution of impurities can be due to the regions with a mechanical stress and radiation stimulated diffusion which occurs in crystal during irradiation. Besides, it is very difficult to explain such significant changes of electromechanical properties as modifications in zone of ion range (some dozens of micrometers) at sample thickness of $1 \mathrm{~mm}$ order. One can assume that structural modifications and impurities redistribution happen to be beyond zone of ion range, that has been observed in LiF crystals [8]. To thorougly define the processes proceeding in piezoelectric crystals at their irradiation by high energy heavy ions, one needs to carry out further investigations required for checking the above mentioned assumptions.

\section{REFERENCES}

1 A. Dunlop and D. Leseuer, Materials Science Forum 97-99 (1992) 553-576.

2 A.M. Zaitzev, Surface Physics Chemistry Mechanics 10 (1991) 5-25 (in Russian).

3 V.R. Regel and al., J. Techn. Phys. V 57, issn. 2 (1987) 306-310 (in Russian).

4 I.P. Kuzmina and V.A. Niketenko, Oxide of Zinc : Production and optical properties (Moscow, Edit. Nauka, 1984), 1-166 (in Russian).

$5 \quad X$. Jaffe and D.A. Berlinkur, Proceedings of Institute of engineers electrotechnics and radioelectronics $V 52, \mathrm{n}^{\circ} 10(1965) 1552$.

6 E.F. Tokarev and al., Fiz. Tverdogo Tela 17 (1975) 980 (in Russian).

7 R.B. Belser and W.H. Hichlin, Proc. Ann. Symp. Frequency Control 15-th Atlantic City, New Jersey, 1961, 138-141.

8 L.L. Regel and al., Phys. Stat. Sol.(a) 73 (1982) 255-266. 